\title{
Supporting the theory of math didactic using knowledge-measuring questions and analysis of the solutions
}

\author{
SÁndor KÁNTOR and PÉTER Fejes-Tóth
}

Abstract. New or rediscovered results presented in this paper are the results of the analysis of the problem sets used in the two-tier system secondary school final examination in mathematics, a system that was introduced in Hungary in 2005.

Many of the revealed problem arise in connection with misunderstanding the text of the problems. Causes of misinterpretation can be either that the text is lacking some important information, or that it should be interpreted not in word-to-word manner.

Theses and their argumentations presented here refer partly on the new types of problems (tests, non-standard mathematical contents), and partly on improvement of learning-teaching process in topics of equations and approximations.

Key words and phrases: analysis of the problem sets, misunderstanding the text of the problems.

ZDM Subject Classification: D20, D50.

\section{Introduction}

Motto: "Don't expect too much from the student.

He won't think through these.

But he also won't be left with the correct image of the whole."

(Tamás Varga) 


\section{Topic and timeliness of the research}

In Hungary the analysis of math education and learning of 14 to 18 year old students gained center stage because since 2005 we apply a novel, two-tier (mid-level and advanced) math graduation exam system.

The new exam has a nationally standardized written section with available solutions which provided an easily accessible, detailed and unified material for this research.

There are several problems raised by this material [6]. The topic of our research is to formulate some theses supported by the analysis of these issues.

At the same time there are expectations towards such testing materials that do not exist for problems used during the teaching process. For example, it has to be clear which answers can be considered correct. This made our work easier, as it simplified the evaluation.

Most of the arising problems we found are concerning text interpretation. Instead of the modern "text comprehension" expression we purposefully use "text interpretation", because everyone understands the text, one way or another, and persons claim that they do not understand it, only because they consider it unusable.

The text of the problem respectively of the solution are often problematic because they are incomplete, and thus can be interpreted in multiple ways, or because the words are not used in their literal meaning.

A study [4] on a smaller focus of our research topic used a similar material and method. The authors of [4] were analyzing the checking of the results in the solutions of two-tier written exams, and used a previous version of [6] and [7]. They also recognized the issue of interpretation, and found the cause of this in the use of undefined concepts. They also noted that the committee that prepared the material was not consistent in dealing with the issues. They found a part of the issues unavoidable or unsolvable.

We find that the issues can be resolved and suggest new conventions instead of new definitions: an agreement (convention) between the text writer and the user about the interpretation of the text.

Convention was always a part of interpreting mathematical text as not everything can be described in detail and precisely [8], [9]. Nowadays it is common to use previously unused descriptions for the problems and their solutions rather than using old ways of formulating, which were unambiguous due to the use of 
familiar conventions. It adds to the confusion that textbooks often use problemsolving strategies that differ not only formally but also conceptually, and often even provide different definitions.

Since we advocate the use of convention to improve the learning-teaching process, our entire manuscript can be viewed as support for the need of conventions.

\section{Methods of the research}

Measuring the level of knowledge by problems means measuring knowledge of performance. Thus, we measure not only the knowledge of the material and methods needed for the solution of the problems, but also the ability of using it effectively. It is an important question whether we measure work or result. In the material we analyzed both aspects are taken in account with approximately equal weight.

We use a method that is the application of an old method in a new environment. It was used about 100 years ago by Manó Beke [3], who recognized the importance of "student mistakes" in understanding and describing the process of math learning, to use current vocabulary: in creating the correct math-didactic theory. His observations were confirmed by modern didactic research. Since then numerous studies were performed with such methods, we refer to a recent work published in the journal Teaching [1].

Using this method in a new environment means that, instead of analyzing the mistakes of the student exams, we analyze the questionable, problematic parts of the test problems themselves and their officially published solutions.

We used the 350 documented problematic cases that were identified in [6] during the analysis of the 432 exam problems and their official solutions given during a period of 8 years, in 4 series of final math exams each year.

While we considered aspects described in [1] in grouping the problems, we mostly grouped based on topics, as this is more in line with the recommendations we make about learning-teaching.

We provide examples for the described issues and indicate their prevalence, which necessitates the correct argumentation. In the suggestions for improvement of the learning-teaching process we also used ref [7], which contains detailed explanations.

When drawing conclusions, we found it important to learn the opinion of teachers about our conclusions. We asked 45 high school teachers to specify which of the provided T1, T2, T4, T5 and T7 theses they found "surely true", "probably true", "probably false", or "surely false". They did not see our analysis, 
argumentations and opinion. We provide the distribution of their answers in the discussion of the theses.

\section{The results of our analysis meet the expectations}

As the theses provide didactically interesting, possible and meaningful explanations for the phenomena revealed during our analysis, they can be viewed as scientific results [10]. While the theses cannot necessarily be considered proven, due to the large size of material analyzed, it can be considered well supported, and as such, worthy of publication and further analysis. Their usefulness is increased by the fact that they provide directly applicable statements concerning the process of learning-teaching.

\section{Motivation of the research}

Textbook reviews are similar to our analysis. The motto was chosen from a textbook review by the famous Hungarian didactician, Tamás Varga. The motto is also a concise illustration of the need to use a language in problems that provides the students with the correct image of the material: A perception that does not lead to incorrect solutions, even if it is not described with the precise vocabulary of higher-level math.

This thought can be well illustrated by the fact that, for 200 years after the discovery of differential and integral calculus, its descriptions were so imprecise, that they would be unacceptable even in current high school textbooks. Nonetheless, mathematicians have achieved outstanding results, because they had the correct perception.

Therefore, when examining a given incomplete text, its all possible extensions, as well as all possible interpretations has to be examined and clarified. Generally, this is not done by the students which can lead to contradictions.

The analysis of problems was aided by the experience Sándor Kántor gained during the grading of final exams (for 35 years), as well as by observing the knowledge freshman students bring from high school (during the 50 years of teaching freshman undergraduates). Péter Fejes-Tóth contributed to the project by providing the high-school teacher's experience and viewpoint required for the analysis.

\section{Description and classification of the results}

The theses and their justifications deal in part with the new problem types and in part with learning-teaching problems that need improvement.

The final exam problems, the theses and their justifications were labeled with $\mathrm{P}, \mathrm{T}$, and $\mathrm{J}$ and a number, respectively. 


\section{Theses concerning new problem types}

General, and as such not specifically math-related, theses can be formulated about the new problem types that appear in the newer final math exams. Here the "type" phrase also does not refer to the mathematical topic but, rather to typical characteristics that are missing or only sporadically occurring in exams of previous years. These types are:

Test questions, • long texts, • application-oriented questions, • non-traditional mathematical context.

In this paper we refer to test questions as questions where only the final result needs to be provided, not the justification.

We do not address the issues of long texts and problem-oriented questions in this manuscript because, while they are didactically important and interesting, they are not connected with interpretation of mathematical text.

In Hungary test questions did not exist in final high school math exams prior to 2005 .

There were incidences when the final exam questions were reformulated to test questions and were given to students as an experiment but these were independent from the final exam. The results of these experimental exams were presented at the meeting discussing experiences obtained during final exams.

The conclusion was that the test questions obtained by reformulating traditional problems measured the knowledge of the students incorrectly. therefore test questions could not be used at final exams. In our opinion this conclusion was incorrect, since only the reformulated traditional questions could not measure correctly the students' knowledge, and not test questions in general. Namely by the reformulation did not change the complex structure of the series of problems, which were building on each other and used the solution of previously solved questions. This way, the answer to the test question was incorrect if an error occurred on one step, though the idea of the solution was correct.

In the new final exam system at least $95 \%$ of the students chose the mid-level exam. One part of this exam is consisting of 12 easily solvable test questions for which 45 minutes are available.

Accordingly, it is an important and interesting question whether a test exam consisting of many short questions can provide realistic assessment of knowledge.

We exclude from our analysis the assessment of the ability to formulate an answer, since this cannot be measured by any test exam. 
Test requiring the solution of many easy problems in short time are used in Hungary in two cases. One of them is a national competition (the so called Zrinyi Competition) introduced some years before the two level final exam, first only only for students of the age between 10 and 14 years, and later for students of age from 6 to 18 years. Thus, Hungarian teachers are familiar with sort of tests. The workshops preparing and selecting the students for the IMO (International Mathematical Olympiad) represent another example for the use of such tests. Here, students are given the AMC (American Mathematics Competition) test which is in the US the first competition for choosing students for the IMO team [2]. Sándor Kántor was the instructor of such workshops between 1965 and 1995, therefore he and the teachers of the best Hungarian students) know well these tests. As the selected students performed well, this justifies the following theses:

T1. Those who can solve a few relatively hard math problems in longer (3-5 hours) time are usually the ones who can solve many small problems (the text of the problem concise and the answers can be formulated briefly) in a short time.

Obviously, we assume that the topic of the problem and the knowledge needed for the solution are identical for the two versions.

J1. T1 is also supported by the experience of Sándor Kántor who observed the birth of the solution of several thousands of difficult problems during the preparatory workshops for the IMO.

In his opinion in most cases hard problems were solved through trying several small ideas and choosing from them the combination of those that work.

This opinion is based on the observation that good problem solvers follow György Pólya's suggestions to vary the problem while solving it: reformulate (for example using algebraic, geometric or logical transformations), change the conditions (for example by leaving away or adding some), etc. This is a lot of work and needs to be done fast.

Because this observation explains why there is a strong correlation between the ability to solve many small problems in a short time and harder problems in longer time, this also provides support for T1.

It is worth mentioning that the validity of $\mathrm{T} 1$ can be observed, besides solving mathematical problems, also in other situations that are related to thinking. We can consider further support for the thesis that the placement of chess competitors only rarely and minimally changes in the fast-paced games that allow limited time to think in comparison to the scores recorded in conventional games. The 
grandmaster never fails. One example to this is the most recent Hungarian fast chess competition (www.chess.hu).

Let's analyze the teacher's opinions about thesis T1.

5 teachers considered T1 "surely true", 20 "probably true", 20 "probably false" and none thought it was "surely false".

Thus, according the opinion of the teachers $\mathrm{T} 1$ does not hold for the majority of the students. The reason for this opinion of the teachers might be that good performance on competitions requires more creativity than the solution of conventional problems on the final exam.

Let's analyze the new Hungarian final exams. 16 of the 32 problems sets referenced in [6] consisted of two parts, one of which was multiple-choice with 12 problems to be completed in 45 minutes. The problems were easy to answer, 74 of the 192 questions could be answered without knowledge of any high school math. In $3 / 4$ of the questions only the end-result was requested and no justification.

For example, one of the problems was:

P1. If $1 / 2 \mathrm{~kg}$ oranges cost $75 \mathrm{HUF}$, then how much orange can one get for 300 HUF?

Those who evaluated the newer exams [5] also found it important to analyze the accomplishments of students independently on the conventional problem sets and on the tests. Based on the available data they concluded that the students performed $20 \%$ better on the tests than in the conventional problem sets.

We use the results of these exams to complement their findings with our observations.

We explain the $20 \%$ improvement in performance not only with the fact that easier problems are given, but also with the extended time for solving the problems: we find 45 minutes too long. Similar performance could have been achieved with the two testing methods if the time for the new tests was reduced because the test results would have only stayed high for those students who can also solve harder problems.

The analysis of the first part of the final exams using tests only shows that it is useful, as it is flexible and easily adaptable to the preferable difficulty.

Let's transition to the issues with non-conventional mathematical content. In texts containing conventional mathematical content our high school education has established the use of words and symbols with the same meaning. 
In higher math it is not uncommon that not only in different countries but also within one country different universities use different definitions for the same concept, that is, the same words have different meaning or interpretation.

The non-conventional mathematical texts almost always use expressions taken from higher math. Accordingly, it is not surprising that the use of non-conventional mathematical content in high school education is almost always accompanied by issues of text-comprehension. We do not question the necessity of such content. However, since this issue poses a didactic problem, we describe our observations on this topic, and the suggested actions in a didactic thesis.

T2. The definitions of notions used in non-conventional mathematical topics, especially the ones of calculus, that were taken from higher math need to be nationally unified in high school education. This is most easily and naturally achieved in textbooks at the introduction of any given topic.

J2. The correctness of the above thesis is supported by the observations in [6] that the non-unified definitions lead to problems in the final exams in 28 cases, although this should not have happened at all.

Most such problems occurred in calculus, so we will introduce a problem from this topic. Occasionally problems arose in other topics as well, e.g. the interpretation of a period of a function, or in graph theory the intermixing of edge and path.

P2. Given is the function $f:[-2 ; 5] \rightarrow R, \quad f(x)=-x^{2}-2 x+3$. Analyze the function in respect to the following aspects: increasing, decreasing, extreme values (location and value)!

The solution guide gives two solutions.

In the first solution, based on reading off of the graph it determines that " $f$ is strictly monotonously increasing in the interval $[-2 ;-1]$ and is strictly monotonously decreasing in the interval $[-1 ; 5]$ ".

In the second solution it finds with differentiation that " $f$ is strictly monotonously increasing in the interval $[-2 ;-1$ [ and is strictly monotonously decreasing in the interval ]-1; 5]".

The official solution notes: "We can include or exclude the value $x=-1$ in the monotonous intervals. Consider both answers correct."

Both solutions writes that

"the maximum is at -1 and its value is 4 , the minimum is at 5 and its value is $-32 . "$ 
There is no mentioning of "global" or "local" extreme values.

For the solution of all types of problems applies the following convention:

In questions with "analyze" the most detailed analysis is expected that can be given based on the curriculum.

Accordingly, the solution is incomplete, as the extent of "in respect to" is not clarified. Only strict monotonicity is mentioned, in the case of the extreme values the question of strict or local extremum is not analyzed. The confusion is deepened by the fact that in the analysis of monotonicity the result is adjusted to the method of the analysis, which based on the text of the problem is unknown.

T2 was considered "surely true" by 19 teachers, "probably true" by 23 teachers, "probably false" by 3 teachers, while none considered it "surely false".

This can be considered as support for the thesis.

\section{Theses related issues of improving the process of learning-teaching}

We put special emphasis on two topics (equations and approximations), on one hand, because with them far more problems occurred (240 from 350) than with other topics, on the other hand, because we attempted to find an explanation for why these topics are so prone to have problems.

It is likely not a coincidence, but rather the consequence of the many issues arising within the topic of equations that [4] is also focusing on a subarea within this topic.

A common feature between equations and approximations is that the teaching and applications of these topics get taught over an extended time period of many years. The questions start very easy, and become very complicated by the end.

At the same time, textbooks are lacking summaries, which fact is supported by the analysis of the issues.

Equations come up as early as elementary school when students have to fill in the blanks: $12+()=17$. Later they find the unknown quantity by elementary calculation. In middle school higher operations or functions appear in equations, the solution mechanisms are adjusted to the properties of these. Equations with text further complicates the issue of the existence and of the checking of the solution.

Complications in the topic of calculations start with the simultaneous introduction of normal fractions and decimal fractions when accuracy and approximation are not analyzed. In high school this means that the consequence of 
inaccurate calculation is not assessed when dealing with more complicated equations that contain irrational numbers. It is simply assumed that the calculator gives always an accurate answer.

The extended teaching period and lack of summaries is also typical in the topic of approximations. Here teaching encompasses the exact definition of new subject aids, forms and carriers, and the use of these, rather than teaching novel mathematical knowledge. Instead of summary we emphasize the need for constant attentiveness.

The fact that in important and complicated topics such as trigonometry, logarithm, arithmetic and geometric progressions, there are far less problems supports that these common features - extended teaching time and lack of summaries - are the cause of many arising issues. These complicated topics are taught in shorter time-span (in Hungary usually within less than half a year) and summaries are provided.

Our arguments are supported by examples of topics where, despite of the extended time-frame, there are no issues arising with the knowledge of the topic, because good summaries are provided in higher grades. Such topic is for example the area and volume calculation.

It is simple to recognize, based on simple statistical comparison of the frequency of issues, which subjects are prone to issues and we provide a meaningful explanation.

T3. If teaching of a subject matter is prolonged and extends over several years and summaries are few or lacking entirely, then the learning-teaching process suffers. In the process of remembering, the supplementary sections, which contain complicated cases, are lost and only the simple cases are recalled.

J3. The statistically significant increase in problems supports the statement that the teaching-learning process suffers.

In the afore-mentioned two topics it is of course impossible to compact processing of the material. However, the issues could be reduced or resolved with high quality summaries.

Thus, one cause of the inefficient teaching-learning is that the extended teaching process is not coupled with emphasized, possibly repeated summarizing.

T4. If teaching of a topic matter is prolonged and extends over several years then an easily memorizable, yet logically accurate summary has to be provided, if needed multiple times, to assure the productive learning-teaching process.

J4. This teaching-learning guideline is obvious. 
T4 was considered "surely true" by 32 teachers, "probably true" by 10 teachers, while only one teacher thought it is "probably false" and none considered it "surely false".

These opinions support the thesis.

We analyze the two problematic topics and provide a summary.

\section{The topic of equations}

For the sake of simplicity we only discuss equations with single variables and both the numbers in the equations and the roots we are looking for will be real numbers. The conclusions obviously can be extended to other equations.

Solving an equation means that we provide the subset of real numbers (the roots including multiple roots) for which the equation holds correct.

This interpretation means that we do not need to provide the domain of the equation (assuming that we will not use it for anything) in the solution. By now this is (probably) accepted convention, but it has not always been the situation.

Previous research [7] has shown that, in combined high school final/university entrance exams given between 1970 and 2000, 82 problem solutions did not use the domain, yet in the case of 42 of them scores were subtracted if the student did not provide it. Based on the study [4] analyzing the solutions to equations in the two-level final exams, members of the committee that assembles the problem sets do not always agree on this question, indicating that this issue is to date still unresolved.

[7] provides the possibly simplest, logically accurate and easily memorizable detailed description of methods that can in most cases be applied for solving equations. The suggested method consists of three parts.

I. At each step of the solution we generate a new equation from the given equation in a way that the successive new equations are consequence-equations of the previous equation. This means that if there is a real number $x$ for which a given equation holds true, then the next equation will also hold true for $x$.

II. The roots of the last equation are obvious.

III. With substitutions we determine whether the roots of the last equation are correct solutions of the original equation.

Based on the analysis of the newer exam questions, the main cause of the recurring problems arising in the official solutions of equations in that the solutions deviate from this system, but not by using another good system. During the teaching process it is critical to emphasize the importance of avoiding such procedures. We provide examples below. 
Typical, recurring problems related to part I:

- The use of phrases (we call them fill words because they are superfluous for solving the equation) between the equations, which do not specify the logical relationship between the equations, at best they indicate what operation is used to obtain the new equation. It would be far more important to describe the logical relationship between the equations, which is often not obvious, rather than the needed operation, which is usually obvious from the new equation.

- If the student only writes equations and does not describe the relationship between, them then it is not clear what the correcting teacher needs to do. This leads to many unclarified problems according to the authors of [5]. Maybe they do not provide solutions to the issues because here conventions would be needed rather than definitions.

- To date, it still happens that the provided solution defines unnecessary domains of equations.

Mutually contradicting use of the domain is provided in the two consecutively published solutions, describing only the essence:

P3. Solve the equation below on the set of real numbers!

$\sqrt{x^{2}+1}+\sqrt{x^{2}-3}=2$

The first sentence of the first solution: "we can only look for solutions under the condition of $x^{2} \geq 3$."

The second solution is searching within all real numbers (does not provide restrictions for $x$ ).

In the first solution it would be more appropriate to write instead of "we can only look for solutions under the condition of $x^{2} \geq 3$." "Let us look for solutions under the condition of $x^{2} \geq 3$."

P4. Solve the following equation! $9^{x}-2 \cdot 3^{x}-3=0$

The first sentence of the solution: "The $a^{2}-2 a-3=0$ equation needs to be solved".

There are other solution strategies as well. Rather than "need to" "we will".

Maybe, these are not serious problems, and they do not cause confusion for the teachers, but these instruction are also used by the students when preparing for the final exam, and they should have the right image. According to the motto in the introduction we should examine such problems as well. 
Typical, recurring problems in instructions for solution, which relate to point III:

- The root(s) of the last equation are called the solution to the first equation and then it checks for correctness. This results in a logical mistake due to the order.

- It proves that one of the two roots of the equation is incorrect and states without proof that the other is correct. It assumes that there has to be a correct root.

- It assumes that comparing the root-candidate with the domain of the equation provides checking of its correctness. However, the fact that the root-candidate is part of the domain does not prove that it is a root.

The specific form of T4 that applies to equation solving is:

T5. During the teaching of equation solving it is important to repeatedly highlight easily memorizable, logically accurate methods, steps of the equation solving process. It needs to be emphasized how mistakes that arise from superficial handling can be avoided.

J5. T5 was considered "surely true" by 37 teachers, "probably true" by 8 teachers and none considered it "probably false" or "surely false".

These opinions support the thesis.

\section{Problems in the subject of calculations}

Problems in this topic definitely need to be clarified as $30 \%$ of the issues arise within this subject. A key question when discussing issues in this field is the use of pocket calculators. This topic is discussed many times and by many [5]. We approach this problem from a different view-point.

As a start we consider the following two theses as indisputable elemental truth, or if you prefer, proven.

T6. Math almost always has a calculation aspect during both its education and its application. This has to be conscientiously accepted, avoiding or circumventing it would result in many disadvantages.

Calculations are often performed with rounded and approximating values.

T7. Every person (who has finished elementary school) needs to know the concept of rounded and approximating values. Accordingly, one needs to know the difference between these two types of numbers, and also needs to distinguish 
between them and exact numbers. The sign of approximating value is $\approx$, there is no sign for rounded numbers, the use of it has to be indicated in the text.

According to [6] problems often arising during calculations are:

- The question is a rounded number, the answer an approximating value (does not answer the question). These are questions, occurring by the score, in which they ask for the solution rounded to some decimal, and the provided solution gives some approximated value (without information to the level of approximation) rounded to the given decimal.

- Maybe they are misprints, but exactly these should be avoided.

$$
\begin{aligned}
& \frac{29}{9}=3,2 \text { instead of } \frac{29}{9} \approx 3,2 . \\
& \frac{29}{9}=3,2 \text { instead of } \frac{29}{9} \approx 3,2 . \\
& \frac{5^{2} \cdot 7,2}{3} \approx 60 \text { instead of } \frac{5^{2} \cdot 7,2}{3}=60 .
\end{aligned}
$$

Let's look at the relevant and educational part of a problem, which cannot be due to a typo.

P7. Which is more probable from two (specifically given, only not detailed here) events? Provide calculations to support your answer!

The official answer is:

"The probability of the first event is: $\approx 0,455$,

the probability of the second event is: $\approx 0,151$.

Accordingly the first event is more likely to occur."

We agreed that the sign $\approx$ does not contain the degree of approximation. The equation $x \approx 0,151$ allows $x=0,7$ as well, in which case the first event is more likely to occur is false.

The truth is that based on an approximate value, without knowing the level of approximation one cannot compare the two values.

Concerning the discussing examples about the issues in the topic of calculations, we conscientiously left it to the end to remark, that these examples are by many considered very serious mistakes, and these people do not understand how such mistakes can occur. They question why we only call these "problems" and not "mistakes". The answer is found in conventions. There are people who think that the $\approx$ sign can mean both approximating value and rounded value and that the reader needs to determine based on the context, which one is meant. 
We admit that with such a convention most of the problems in calculation are not problematic, however, we cannot accept such a convention. Here we limited ourselves to call the phenomenon a problem and not a mistake but we find it impossible to resolve it with such a convention.

The correctness of T7 is not a topic of discussion and not a question of consideration but a question of curricular requirements. And the curriculum considers it unequivocally correct. For example a detail from the 7th grade curriculum:

"Approximating numbers, numbers referring to an interval. Approximating calculations. Addition, subtraction, multiplication and division with approximating values. (how many digits are reliable? Until what digit is it worth to calculate?)"

T7 was considered "surely true" by 8 teachers, "probably true" by 25 teachers, "probably false" by 8 teachers and "surely false" by 4 teachers.

We do not analyze the interpretation of $\mathrm{T} 7$, only comment that the teacher who considered it "surely false" might have thought that many of their students have finished elementary school and do still not know these notions. We think that all their students surely know them if something important depends on this knowledge.

\section{Summary}

We consider it crucial to stress the importance of a mathematical mind-set during the phrasing of the described theses and during the implementation of the suggested theses. This, together with the correct picture about the math curriculum will enable easy navigation amongst the problems. If (according to Hungarian traditions) we teach/learn creative math, then there will be obvious problems and obvious solutions in exams.

We noted during the discussion of tests what we consider a good test and that only good tests are worth consideration.

With the newer and harder math curriculum we can and need to achieve the correct image by forming the essence.

When dealing with equations once again the essence and not the form is important. In the solutions the proof is essential, this cannot be damaged.

When calculating, we need to know what we have calculated. What is the relationship of the calculated value to the value we are looking for? 


\section{References}

[1] G. Ambrus and K. Szücs, Fehleranalyse beim Lősen von offenen Aufgaben-Ergebnisse einer empirischen Studie in der Grundschule, Teaching Mathematics and Computer Science 14, no. 1 (2016), 83-113.

[2] G. Berzsenyi and E. Hódi, Annual High School Mathematics Examination, A Matematika Tanítása 2 (1979), 53-59.

[3] Homepage of Mihály Fazekas High School (Budapesti Fazekas Mihály Gimnázium honlapja) https://fazekes.hu.

[4] Cs. Csapodi, L. Koncz, T. Kósa and Gy. Orosz, The role of checking in the guidelines to the grading of the final exams (Az ellenőrzés kérdésköre a matematikai érettségi vizsga javítási-értékelési útmutatóiban), Középiskolai Matematikai és Fizikai Lapok 65, no. 8 (2015), 454-458 http://goo.gl/7VLzHz.

[5] Cs. Csapodi and L. Koncz, Efficiency and the use of calculator at the final exam (Eredményesség és számítógéphasználat az érettségi vizsgán), Rátz László Vándorgyülés, Baja, 2016 http://www.bolyai.hu.

[6] S. Kántor, Errata to the final exams (Az érettségi példasorok hibajegyzéke) http://www. math. unideb.hu/kantor-sandor.

[7] S. Kántor, Methods and expectations (Módszerek és elvárások), Studium '96 Bt, Debrecen, 2001.

[8] S. Kántor and A. K. Fazekas, Conventions of mathematical problems and their solutions in Hungarian secondary school final exams, Teaching Mathematics and Computer Science 9, no. 1 (2012), 137-146.

[9] T. Kántor, On mathematical competition tests I. (Matematikai versenytesztekről I.), A Matematika Tanítása 4 (2002), 8-15.

[10] A.Z. Krygowska, Main trends and problems of contemporary research of mathematical didactics (Krygowska A.Z. Glówne problemy i kierunki badan wspólczesnej dydaktyki matematyki), Dydaktyka Matematyki 1 (1982), 7-60.

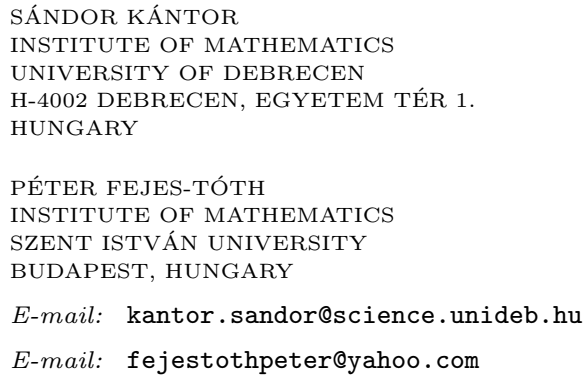

